Working Paper/Document de travail

2008-13

\title{
Uncertainty, Inflation, and Welfare
}

by Jonathan Chiu and Miguel Molico 
Bank of Canada Working Paper 2008-13

May 2008

\title{
Uncertainty, Inflation, and Welfare
}

\author{
by \\ Jonathan Chiu and Miguel Molico \\ Monetary and Financial Analysis Department \\ Bank of Canada \\ Ottawa, Ontario, Canada K1A 0G9 \\ jchiu@bankofcanada.ca \\ mmolico@bankofcanada.ca
}

Bank of Canada working papers are theoretical or empirical works-in-progress on subjects in economics and finance. The views expressed in this paper are those of the authors.

No responsibility for them should be attributed to the Bank of Canada. 


\section{Acknowledgements}

We have benefited from the comments and suggestions from Ennis Huberto, Per Krusell, Cesaire Meh, Randall Wright, and from participants at the CEA Meetings in Halifax, the Far Eastern Econometric Society Meeting in Taipei, the Midwest Macroeconomics Conference in Cleveland, the Money, Banking, Payments and Finance Conference at the Cleveland Fed, the Society of Economics Dynamics Conference in Prague, and the Workshop on "Optimal Monetary Policy and Central Bank Communication” in Switzerland. 


\begin{abstract}
This paper studies the welfare costs and the redistributive effects of inflation in the presence of idiosyncratic liquidity risk, in a micro-founded search-theoretical monetary model. We calibrate the model to match the empirical aggregate money demand and the distribution of money holdings across households, and study the effects of inflation under the implied degree of market incompleteness. We show that in the presence of imperfect insurance the estimated long-run welfare costs of inflation are on average $40 \%$ smaller compared to a complete markets, representative agent economy, and that inflation induces important redistributive effects across households. For example, the welfare gains of reducing inflation from $10 \%$ to $0 \%$ is $0.59 \%$ of income. Furthermore, we estimate that the long-run welfare gains of reducing the typical current inflation target of 2 to 1 percent to be $0.06 \%$ of income.

JEL classification: E40, E50

Bank classification: Inflation: costs and benefits; Monetary policy framework
\end{abstract}

\title{
Résumé
}

Les auteurs étudient les conséquences de l'inflation sur le bien-être et sur la répartition des revenus en présence d'un risque de liquidité idiosyncrasique, dans le cadre d'un modèle monétaire fondé microéconomiquementet et inspiré de la théorie de la recherche. Après avoir étalonné le modèle de façon à reproduire la demande de monnaie totale observée et la répartition des encaisses monétaires entre les ménages, ils examinent les effets de l'inflation compte tenu du degré d'incomplétude implicite des marchés. Ils montrent que, si l'on ne peut s'assurer parfaitement contre les risques, les effets négatifs de l'inflation sur le bien-être en longue période sont en moyenne inférieurs de $40 \%$ à ce qu'ils seraient selon un modèle à agent représentatif et à marchés complets; ils constatent également que l'inflation entraîne une redistribution importante des encaisses entre les ménages. Ainsi, le gain de bien-être réalisé en ramenant l'inflation de $10 \%$ à $0 \%$ représente $0,59 \%$ du revenu. Les auteurs estiment en outre que, si la cible d'inflation était fixée à $1 \%$ au lieu des $2 \%$ habituels, le gain équivaudrait à $0,06 \%$ du revenu.

Classification JEL : E40, E50

Classification de la Banque : Cadre de la politique monétaire; Inflation : coûts et avantages 


\section{Introduction}

The aim of most central banks in recent years has been to target a low positive long-run inflation rate in a range of 1 to 3 percent. Yet, the welfare benefits and/or costs of such practice still lacks theoretical foundations and are not fully understood. The traditional textbook models with complete, perfect markets, infinitely-lived households and the possibility to levy lump-sum taxes, imply that Friedman's Rule - setting the nominal interest rate to zero - is generally optimal. In such environments, inflation is always costly in terms of welfare by serving as a distortionary tax on money holdings. In this paper we abandon the assumption of complete markets and analyze the effects of inflation in an environment where agents are subject to uninsurable idiosyncratic liquidity risk and can only partially undo their trading histories. In such an environment, although inflation still serves as a distortionary $\operatorname{tax}$ (i.e. the traditional "real balance effect"), there is a potential welfare improving effect of redistributive expansionary monetary policy - it can mitigate the welfare costs of inflation by redistributing liquidity from agents with excess liquidity to agents that are liquidity constrained.

We build on Lagos and Wright (2005) to develop a micro-founded search-theoretical monetary model that emphasizes two empirically plausible features of an economy. First, economic agents face idiosyncratic uncertainty regarding their productivity, preferences, and trading opportunities. Second, agents are unable to insure against such risk due to some degree of market incompleteness implied by the frictions in the economy that make money essential. These features introduce some technical challenges since as a result of the agents' heterogenous trading histories in a decentralized market one needs to keep track of a nondegenerate distribution of money holdings. Lagos and Wright(2005) side-step this problem by assuming that agents trade general goods in a centralized market periodically and have quasilinear preferences over these goods. ${ }^{1}$ These assumptions imply that agents can fully undo

\footnotetext{
${ }^{1}$ Alternatively, one can assume a general utility function as long as one assumes indivisible labor and allow agents to trade lotteries a la Rogerson (1988) following Rocheteau et al. (2005).
} 
their idiosyncratic trading histories in the decentralized market, killing many potentially interesting properties of standard search models. First, in a Lagos-Wright economy, money is perfectly neutral and the model is unable to generate any short run dynamics in response to an one-time money injection. Second, by forcing the money distribution to be degenerate, the model precludes discussions of any distributional effects of monetary policy. Third, this model loses the interesting feature that inflation can provide an insurance function: Friedman's Rule is always optimal in the Lagos-Wright economy. We generalize the Lagos and Wright model by relaxing their restrictive assumption of quasi-linear preferences and use data on the empirical aggregate money demands, and the distribution of money holdings across households for the U.S. and Canadian economies to calibrate the parameters of the model. We find that setting the Frisch elasticity of labor supply in the centralized market to one-half can imply a money demand that fits best the U.S. time series data. We interpret the fact that the estimated Frisch elasticity for the United States is exactly one-half as further support to our calibration. Furthermore, we present some evidence that the dispersion of money holdings across households implied by our calibration is consistent with the empirical money distribution. Note that a finite Frisch elasticity of labor implies that agents are not able to fully undo their idiosyncratic trading histories, which we interpret as a certain degree of market incompleteness. ${ }^{2}$ As a consequence agents will be heterogenous with respect to their money holdings, in equilibrium.

We show that, given the implied degree of market incompleteness, the long-run welfare costs of low and moderate inflations are on average $40 \%$ smaller compared to a representative agents (complete markets) economy. For example, we estimate the gains of decreasing inflation from $10 \%$ to zero percent to be $0.59 \%$ of income, significantly lower than Lucas (2000) estimate of $\simeq 1 \%$ or Lagos and Wright estimate of $1.3 \% .^{3}$ Considering the more pol-

\footnotetext{
${ }^{2}$ Note that, an agent's state variable is his/her money holdings which summarizes his/her trading history, and that the Frisch elasticity measures the willingness of agents to adjust their labor supply in order to replenish their money balances, undoing their idiosyncratic trading histories.

${ }^{3}$ Here we consider Lagos and Wright estimate under the same pricing mechanism as we use - take-it-orleave-it-offers by buyers.
} 
icy relevant exercise of decreasing the long-run inflation target from $2 \%$ to $1 \%$, we estimate the welfare gains to be $0.06 \%$ of income. ${ }^{4}$

The intuition of the findings is that, in this environment, the idiosyncratic liquidity shocks and non quasi-linear preference imply that agents may not be willing to fully undo their past trading histories, leading to a non-degenerate money distribution. As a result, expansionary monetary policy can improve welfare through its redistributive effect (See Levine (1991), Deviatov-Wallace (2001), Molico (2006)). As the welfare gain from such redistributive effect partially offsets the welfare loss due to the "real balance effect", the net welfare cost of inflation is lower than that in standard representative agent models. Moreover, as the inflation rate increases, the money distribution becomes less dispersed. As a result, the marginal redistribution effect of inflation is diminishing in the inflation rate.

The rest of the paper is organized as follows. Section 2 describes the environment. Section 3 defines an equilibrium. Section 4 discusses the numerical algorithm used to compute the stationary equilibria of the model. In section 5 , to facilitate the comparison of our results to the existing literature, we calibrate the model to match the empirical money demand for the U.S. economy and study the welfare cost of inflation. Section 6 concludes the paper.

\section{The Model}

Time is discrete and denoted by $t=0,1,2, \ldots$. There are two types of non-storable commodities: general and special goods. The economy consists of a continuum $[0,1]$ of agents. The per-period utility of an agent is given by

$$
U\left(X_{t}\right)-C\left(Y_{t}\right)+u\left(x_{t}\right)-c\left(y_{t}\right)
$$

where $U(X)$ denotes the utility of consuming $X$ units of the general good, $C(Y)$ denotes the disutility of producing $Y$ units of the general good, $u(x)$ denotes the utility of consuming $x$

\footnotetext{
${ }^{4}$ This estimate, however, ignores any transitional costs/benefits of such policy change which is a question we are currently investigating in a companion paper.
} 


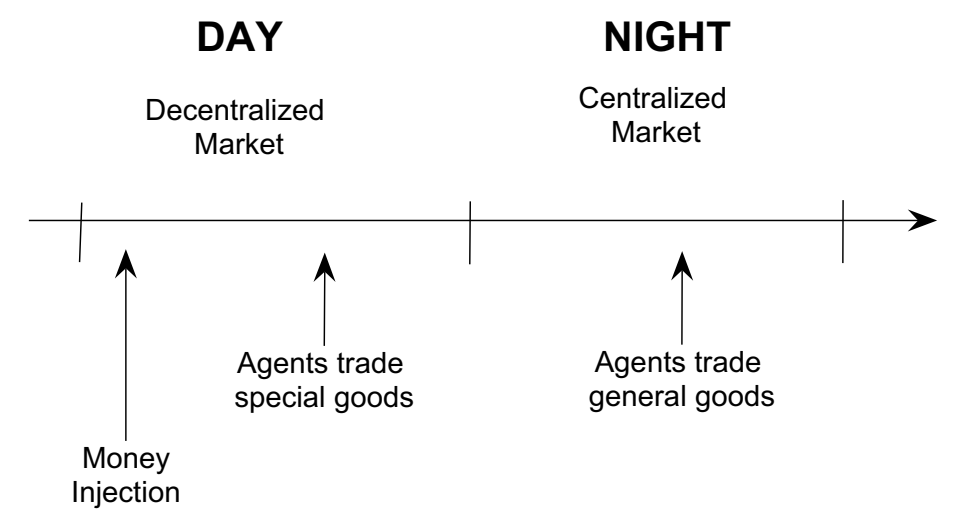

Figure 1: Time line

units of the special good and $c(y)$ denotes the disutility of producing $y$ units of the special good. We assume that $u($.$) and U($.$) are twice continuously differentiable, strictly increasing,$ strictly concave, and satisfies $U(0)=0, U^{\prime}(\bar{X})=1$ for some $\bar{X}>0, u^{\prime}(\bar{x})=1$ for some $\bar{x}>0$. Also, $C(Y)$ is increasing and strictly convex, and $c(y)=y$. Discount factor is $\beta \in(0,1)$.

In this economy, there is an additional, perfectly divisible, and costlessly storable object which cannot be produced or consumed by any private individual, called fiat money. Agents can hold any non-negative amount of money $\hat{m} \in \mathbb{R}_{+}$. The money stock at the beginning of period $t$ is denoted $M_{t}$. In what follows we express all nominal variables as fractions of the beginning of the period money supply (before the current period's money transfers which we will describe below), $m \equiv \frac{\hat{m}}{M}$. Let $\nu_{t}: \mathfrak{B}_{\mathbb{R}_{+}} \rightarrow[0,1]$ denote the probability measure associated with the money (as a fraction of the beginning of period money supply) distribution at the beginning of period $t$, where $\mathfrak{B}_{\mathbb{R}_{+}}$denotes the Borel subsets of $\mathbb{R}_{+}$.

Each period is divided into two subperiods: day and night. In the day time, there is a decentralized market for trading special goods. In the night time, there is a centralized market for trading general goods (see Figure 1).

As in standard search-theoretical models of money, in the decentralized market, agents are subject to trading frictions modeled as pairwise random matching. To generate the need for trade, we assume that agents cannot consume their own production of special goods. To generate the use of money, we assume that the probability of having a double coincidence of 
wants meeting is zero and that all trading histories are private information. ${ }^{5}$ The probability that an agent consumes something his/her match partner produces is $\sigma \in\left[0, \frac{1}{2}\right]$. Similarly, the probability that an agent produces something that his/her match partner consumes is $\sigma$. Therefore, with a probability $1-2 \sigma$, trading partners do not want each other's goods. When two individuals meet and one consumes the good the other produces, they bargain over the amount of output and the amount of money to be traded. Let $q_{t}\left(m_{b}, m_{s} ; \nu_{t}\right) \geq 0$ be the amount of output and $d_{t}\left(m_{b}, m_{s} ; \nu_{t}\right) \geq 0$ the amount of money determined by the bargaining process at date $t$ between a buyer with money holdings $m_{b}$ and a seller with $m_{s}$, when the probability measure at the beginning of the period is $\nu_{t}$. In particular, the terms-of-trade are assumed to be determined by take-it-or-leave-it offers by the buyers. ${ }^{6}$ Let $\omega_{t}: \mathfrak{B}_{\mathbb{R}_{+}} \rightarrow[0,1]$ denote the probability measure over money holdings at the entrance of the centralized market (after trade in the decentralized market).

Agents take the price of money in terms of the general good in that market, $\phi_{t}$, as given, and decide how much of the general good to consume and produce, and how much money holdings to carry into the decentralized market the next day. Given the environment, the only feasible trades during the day are the exchange of special goods for money and at night barter in general goods or the exchange of general goods for money.

The money stock is assumed to grow at a constant growth rate $\mu=\frac{M_{t}}{M_{t-1}}$ for all $t$. Money growth is accomplished via money transfers at the entrance of the decentralized market. Given the distribution $\nu_{t}$, an agent with money holdings $m$ receives a monetary transfer at the beginning of the period $t$ decentralized market, $\tau\left(m, \nu_{t}\right)$ (as in Lagos-Wright or Molico). We assume that the monetary transfers (monetary policy rule) are such that rate of monetary

\footnotetext{
${ }^{5}$ For money to be valued it is only required that in some meetings there is no double coincident of wants. For simplicity, we focus on purely monetary trades and, by assumption, preclude the possibility of barter in the decentralized market.

${ }^{6}$ More generally, we could consider that the terms of trade were determined by the solution of a generalized Nash-bargaining problem as in Lagos-Wright. As shown in that paper, if the seller has some bargaining power additional distortions exist that would imply higher welfare costs of inflation. The same would be true here. In that sense, we provide a lower bound for the welfare costs of inflation.
} 
growth is constant over time.

$$
\mu \equiv \int_{0}^{\infty}\left[m+\tau\left(m, \nu_{t}\right)\right] \nu_{t}(m) d m
$$

This concludes the description of the environment. In what follows, we will gradually build towards the definition of equilibrium.

\section{Equilibrium}

In this section we define a recursive equilibrium for this economy. We begin by describing the individual and aggregate state variables. An individual's state variable consists of his/her money holdings (as a fraction of the beginning of the period money supply). The aggregate state variable is, in turn, defined as the current probability measure over money holdings. Thus, at the beginning of the period an individual's state is described by the pair $(m, \nu)$, and at the entrance of the centralized market by $(m, \omega)$. Agents take as given the law of motion of the aggregate state variable defined by $\nu^{\prime}=H_{\nu}(\omega)$ and $\omega=H_{\omega}(\nu)$ which we will describe in detail below, where prime denotes the future period. ${ }^{7}$ Also, agents take as given the price of money in units of the general good in the centralized market, $\phi$, as a function of the current aggregate state, $\phi: \Lambda \rightarrow \mathbb{R}_{+} \backslash\{0\}$, where $\Lambda$ denotes the space of probability measures over $\mathfrak{B}_{\mathbb{R}_{+}} \cdot{ }^{8}$ Finally, agents take as given the monetary policy rule (transfers) $\tau: \mathbb{R}_{+} \times \Lambda \rightarrow \mathbb{R}$.

\subsection{The Centralized Market}

In what follows we first describe the value function of agents at the entrance of the centralized market.

Consider the expected lifetime utility of an agent in the centralized market, $W(m, \omega)$, where $m$ is the money balance held by the agent normalized by the beginning-of-the-period

\footnotetext{
${ }^{7}$ Equivalently, define the law of motion of the aggregate state variable by $\nu^{\prime}=H(\nu) \equiv H_{\nu}\left(H_{\omega}(\nu)\right)$.

${ }^{8}$ Note that by restricting $\phi$ to be strictly positive, we focus on only monetary equilibrium in which money has value.
} 
money stock. Given the price of money, $\phi(\omega)$, and the monetary policy rules, the value function is given by

$$
\begin{aligned}
& W(m, \omega)=\max _{X, Y, m_{+1} \geq 0} U(X)-C(Y)+\beta V\left(m_{+1}, \nu^{\prime}\right) \\
& \text { s.t. } \\
& Y \geq X+\phi(\omega)\left[m_{+1} \mu-m\right] \\
& \nu^{\prime}=H_{\nu}(\omega),
\end{aligned}
$$

where $V(m, \nu)$ is the value function for an agent at the beginning of the day with money balances $m$ when the aggregate state is $\nu .{ }^{9}$ Given the individual state $m$ and aggregate state $\omega$, an agent chooses the optimal amounts of the general good consumption $(X)$, the general good production $(Y)$, as well as the money holding at the entrance of the next decentralized market $\left(m_{+1}\right)$. The budget constraint simply states that the expenditure on consumption and on net money purchase is no greater than the income from production.

In equilibrium, choices of money holdings, $m_{+1}(m, \omega)$, satisfy the money market clearing condition,

$$
\int_{0}^{\infty}\left[m_{+1}(m, \omega)-m\right] \omega(d m)=0 .
$$

\subsection{The Decentralized Market}

We now consider the bargaining problem of an agent in the decentralized market. Consider a single coincidence meeting when a buyer holds a money balance $m_{b}$ and a seller holds a balance $m_{s}$, after the decentralized market's money injection, when the aggregate state is $\nu$. We assume that the buyer makes a take-it-or-leave-it offer to the seller. That is, he/she

\footnotetext{
${ }^{9}$ In what follows, we will assume that $V(\cdot, \omega)$ is a continuous function. By the Theorem of the Maximum, $W(\cdot, \omega)$ is a continuous function and the set of optimizers is a nonempty, compact-value, and an u.h.c. correspondence. By the Measurable Selection Theorem, define $m_{+1}(m, \omega), X(m, \omega), Y(m, \omega)$ to be a measurable section of such correspondence.
} 
proposes a trade of an amount of money, $d$, for a quantity of special good, $q$, that solve the following problem:

$$
\max _{q \geq 0,0 \leq d \leq m_{b}} u(q)+W\left(m_{b}-d, H_{\omega}(\nu)\right)
$$

subject to

$$
-q+W\left(m_{s}+d, H_{\omega}(\nu)\right)=W\left(m_{s}, H_{\omega}(\nu)\right)
$$

Or, equivalently, by substituting the latter constraint into the objective function,

$$
\max _{0 \leq d \leq m_{b}} u\left[W\left(m_{s}+d, H_{\omega}(\nu)\right)-W\left(m_{s}, H_{\omega}(\nu)\right)\right]+W\left(m_{b}-d, H_{\omega}(\nu)\right)
$$

The buyer makes an offer to maximize his/her surplus subject to making the seller indifferent between trading and not trading. Note that, given that $W\left(\cdot, H_{\omega}(\nu)\right)$ is a continuous function, the objective function of the bargaining problem is continuous. Also, the set $d \in\left[0, m_{b}\right]$ is non-empty and compact. Thus, by the Theorem of the Maximum and the Measurable Selection Theorem the set of optimizers is a non-empty, compact-valued, and u.h.c. correspondence and admits a measurable a selection. Define $d\left(m_{b}, m_{s}, \nu\right)$ to be such selection. The function $q\left(m_{b}, m_{s}, \nu\right)$ can then be obtained from the seller's participation constraint.

The expected lifetime utility of an agent that enters the period with money balance $m$ (before the decentralized market money injection) is given by

$$
\begin{aligned}
V(m, \nu)=(1-\sigma) W[m & \left.+\tau(m, \nu), H_{\omega}(\nu)\right]+\sigma \int_{0}^{\infty}\left\{u\left[q\left(m+\tau(m, \nu), m_{s}, \nu\right)\right]\right. \\
& \left.+W\left\{m+\tau(m, \nu)-d\left[m+\tau(m, \nu), m_{s}, \nu\right], H_{\omega}(\nu)\right\}\right\} \nu\left(d m_{s}\right) .
\end{aligned}
$$

The first term is the value for an agent that either is a seller, with probability $\sigma$, and thus has a zero net surplus from trade, or meets no one, with probability $1-2 \sigma$. The second term is the expected value of being a buyer. 


\subsection{Laws of Motions}

Before defining a recursive equilibrium for this economy, we describe the laws of motion $\nu^{\prime}=H_{\nu}(\omega)$ and $\omega=H_{\omega}(\nu)$. We begin by describing the evolution of the aggregate state from the beginning of the centralized market to the beginning of the next decentralized market, $H_{\nu}$. Define the function $\Pi: \mathbb{R}_{+} \times \mathfrak{B}_{\mathbb{R}_{+}} \rightarrow[0,1]$ to be

$$
\Pi(m, B ; \omega)= \begin{cases}1, & m_{+1}(m, \omega) \in B \\ 0, & \text { otherwise }\end{cases}
$$

Given that, for each $m, \Pi(m, \cdot ; \omega)$ is a probability measure on $\left(\mathbb{R}_{+}, \mathfrak{B}_{\mathbb{R}_{+}}\right)$, and, for each $B \in \mathfrak{B}_{\mathbb{R}_{+}}, \Pi(\cdot, B ; \omega)$ is a $\mathfrak{B}_{\mathbb{R}_{+}}$-measurable function, $\Pi$ is a well-defined transition function. Then, the law of motion $H_{\nu}(\cdot)$ can be defined as

$$
\nu^{\prime}(B)=H_{\nu}(\omega)(B) \equiv \int_{0}^{\infty} \Pi(m, B ; \omega) \omega(d m) \forall B \in \mathfrak{B}_{\mathbb{R}_{+}} .
$$

We now describe the evolution of the aggregate state from the beginning of the decentralized market to the beginning of the centralized market. Let $T=\{$ buyer, seller, neither $\}$ and define the space $(T, \mathfrak{T})$, where $\mathfrak{T}$ is the $\sigma$-algebra. Define the probability measure $\psi: \mathfrak{T} \rightarrow[0,1]$, with $\psi($ buyer $)=\psi($ seller $)=\sigma$, and $\psi($ neither $)=1-2 \sigma$. Then, $(T, \mathfrak{T}, \psi)$ is a measure space. Define an event to be a pair $e=(t, m)$, where $t \in T$ and $m \in \mathbb{R}_{+}$. Intuitively, $t$ denotes an agent's trading status and $m$ the money holdings of his current trading partner. Let $(E, \mathfrak{E})$ be the space of such events, where $E=T \times \mathbb{R}_{+}$and $\mathfrak{E}=\mathfrak{T} \times \mathfrak{B}_{\mathbb{R}_{+}}$. Furthermore, let $\xi: \mathfrak{E} \rightarrow[0,1]$ be the product probability measure. Define the mapping $\gamma(m, e): \mathbb{R}_{+} \times E \rightarrow \mathbb{R}_{+}$, where

$$
\gamma(m, e)= \begin{cases}m+\tau(m, \nu)-d\left[m+\tau(m, \nu), \cdot H_{\omega}(\nu)\right], & \text { if } e=(\text { buyer }, \cdot) \\ m+\tau(m, \nu)+d\left[\cdot, m+\tau(m, \nu), H_{\omega}(\nu)\right], & \text { if } e=(\text { seller }, \cdot) \\ m+\tau(m, \nu), & \text { otherwise }\end{cases}
$$


We can now define $P: \mathbb{R}_{+} \times \mathfrak{B}_{\mathbb{R}_{+}} \rightarrow[0,1]$ to be

$$
P(m, B ; \nu) \equiv \xi(\{e \in E \mid \gamma(m, e) \in B\})
$$

Again, $P$ is a well defined transition function. ${ }^{10}$ Then,

$$
\omega(B)=H_{\omega}(\nu)(B) \equiv \int_{0}^{\infty} P(m, B ; \nu) \nu(d m) \forall B \in \mathfrak{B}_{\mathbb{R}_{+}}
$$

Finally, we can describe the law of motion of the aggregate state over the two markets as

$$
\left.\nu^{\prime}(B)=H(\nu)(B) \equiv \int_{0}^{\infty} \int_{0}^{\infty} \Pi\left[\bar{m}, B ; H_{\omega}(\nu)\right] P(m, d \bar{m} ; \nu)\right] \nu(d m) \forall B \in \mathfrak{B}_{\mathbb{R}_{+}} .
$$

\subsection{Recursive Equilibrium}

We are finally ready to define a recursive equilibrium for this economy.

Definition 1 (Recursive Equilibrium) A recursive equilibrium is a list of:

Pricing function: $\phi: \Lambda \rightarrow \mathbb{R}_{+} \backslash\{0\}$;

Monetary Policy Function: $\tau: \mathbb{R}_{+} \times \Lambda \rightarrow \mathbb{R}$;

Law of motion: $H: \Lambda \rightarrow \Lambda$;

Value functions: $V: \mathbb{R}_{+} \times \Lambda \rightarrow \mathbb{R}$ and $W: \mathbb{R}_{+} \times \Lambda \rightarrow \mathbb{R}$

Policy functions: $X: \mathbb{R}_{+} \times \Lambda \rightarrow \mathbb{R}_{+}, Y: \mathbb{R}_{+} \times \Lambda \rightarrow \mathbb{R}_{+}$, and $m_{+1}: \mathbb{R}_{+} \times \Lambda \rightarrow \mathbb{R}_{+} ;$

Terms of Trade: $q: \mathbb{R}_{+} \times \mathbb{R}_{+} \times \Lambda \rightarrow \mathbb{R}_{+}$and $d: \mathbb{R}_{+} \times \mathbb{R}_{+} \times \Lambda \rightarrow \mathbb{R}_{+}$;

such that:

1. given the pricing function, the monetary policy functions, the law of motion, the terms of trade, and the policy functions, the value functions satisfy the functional equations (2) and (5);

2. given the value functions, the pricing function, the monetary policy functions, and the

\footnotetext{
${ }^{10}$ By construction, for each $m, P(m, \cdot ; \nu)$ is a probability measure on $\left(\mathbb{R}_{+}, \mathfrak{B}_{\mathbb{R}_{+}}\right)$. Furthermore, given the measurability of $d(\cdot, \cdot ; \nu), P(\cdot, B ; \nu)$ is a $\mathfrak{B}_{\mathbb{R}_{+}}$-measurable function.
} 
law of motion of the aggregate state, the policy functions solve (2);

3. given the value functions, the terms of trade solve (4);

4. given the terms of trade and the monetary policy functions, the law of motion of the aggregate state is defined by (7);

5. given the value functions, the monetary policy functions satisfy (1);

6. the centralized market clearing condition, (3), is satisfied.

In the remainder of the paper we will only focus on stationary equilibria, where, $\nu=H(\nu)$.

\section{Numerical Algorithm}

In this section we briefly present the numerical algorithm developed for finding stationary monetary equilibria of the model and discuss some computational considerations. The basic strategy of the algorithm is to iterate on a mapping defined by the value function equations (2) and (5) and the law of motion of the aggregate state given by equation (7). Special care is taken in keeping track of the distribution of wealth and its composition across iterations. In particular, we keep track of a large sample of agents' money balances and use non-parametric density estimation methods. A Fortran 90 version of the code is available from the authors by request. We begin the algorithm at the entrance of the centralized market.

A brief description of the algorithm follows:

Step 1. Given an initial guess for the distribution of money holding at the entrance of the centralized market, draw a large sample of agents' money balance. ${ }^{11}$

Step 2. Define a grid on the state space of money holdings and an initial guess for the value function at the entrance of the decentralized market, $V^{0}(m)$, by defining the value of the function at the gridpoints and using interpolation methods to evaluate the function at any other point. ${ }^{12}$

\footnotetext{
${ }^{11}$ In all the numerical exercises we use a sample of 10000 agents.

${ }^{12}$ We use a grid of 30 gridpoints unevenly spread so as to capture well the change in concavity of the value function. We experimented with increasing the number and location of the gridpoints without significant quantitative or qualitative implications for our results. An Akima interpolation method from the IMSL
} 
Step 3. Given the sample of money holdings at the entrance of the centralized market and the value function at the entrance of the decentralized market, find the market clearing price by solving the centralized market problem for all agents in the sample and iterating on $\phi$, given an initial guess, until the market clears.

Step 4. Given these, the function $W($.$) is given by (2) .$

Step 5. Given the market-clearing price, update the money holding of the agents by solving their optimization problem. The distribution of money holding at the decentralized market is estimated using Gaussian kernel non-parametric density estimation methods. ${ }^{13}$

Step 6. Given the value function $\mathrm{W}($.$) and the distribution of money holdings at the$ entrance of the decentralized market, update the value function $V(m)$ by using the mapping defined by equation (5) to compute its value at the new gridpoints and re-estimating the interpolant coefficients.

Step 7. For each individual on the sample, update their money holding by simulating their meetings to derive the distribution at the entrance of the centralized market.

Repeat steps 3 to 7 until convergence is achieved.

\section{$5 \quad$ Numerical Results}

In what follows we use the numerical algorithm presented in the last section to find and characterize stationary equilibria of the model. In particular, we characterize the typical features of a stationary equilibrium of the model and illustrate the effects of inflation.

We adopt the following functional forms for the utility and cost functions. In the decenfortran routines was used to keep track of all functions.

${ }^{13}$ To deal with the fact that the money holdings choices of the participants might imply the existence of mass points in the distribution we introduce a very small perturbation (a find a penny- lose a penny assumption) in their optimal choice to smooth the distribution allowing the usage of the Gaussian kernel estimation method. 
tralized market, the utility of consumption is:

$$
u(x)=\frac{(x+b)^{1-\eta}-b^{1-\eta}}{1-\eta},
$$

and the cost of production is normalized to be

$$
c(y)=y \text {. }
$$

In the centralized market, the utility of consumption is given by:

$$
U(X)=B \log (X)
$$

and the cost of production is given by

$$
C(Y)=\frac{Y^{1+\frac{1}{\chi}}}{1+\frac{1}{\chi}} .
$$

Our objective is to parameterize the model in order to match the velocity of money (i.e. the money demand to GDP ratio) implied by the data. Note however that, in the model, the velocity of money is affected by several parameters. In particular, it is affected by the curvature parameter $\eta$, by the arrival rate $\sigma$, the choice of the length of a period (or equivalently, $\beta$ ). Furthermore, most of these parameters are not observable. In the absence of other clear targets, the parameters are not perfectly identifiable from the data. As such, in the exercises that follow we fix some of the parameters. For the exercises below we set $b \simeq 0$ and $\eta=0.99$, and thus the utility function is close to log. We pick $\sigma=0.5$ to minimize the search frictions. We define the length of a period to be one year and set the discount factor to $\beta=0.96$ implying an annual real interest rate of 4 percent. Given the length of the period, we choose $B$ and $\chi$ such that the income velocity of money is around 5 for two percent inflation, and around 7 for ten percent inflation, matching the U.S. historical data. Table 1 summarizes the parameter values used. It turns out that setting $\chi$ to 0.5 and $B$ 
Table 1: Parameter Values

\begin{tabular}{|c|c|}
\hline Parameter & Value \\
\hline \hline$\sigma$ & 0.5 \\
$\beta$ & 0.96 \\
$B$ & 5 \\
$b$ & 0.0001 \\
$\eta$ & 0.99 \\
$\chi$ & 0.5 \\
\hline
\end{tabular}

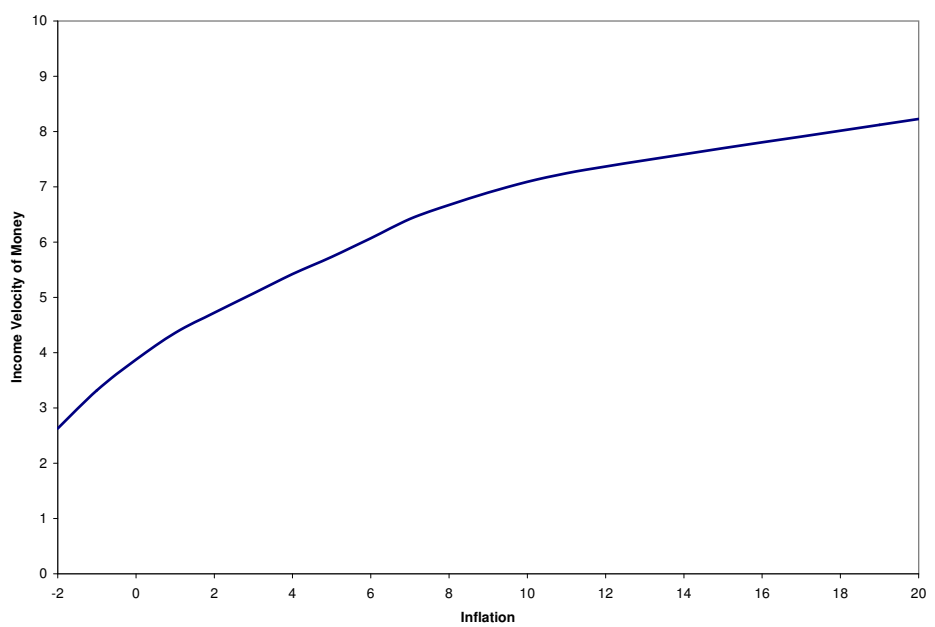

Figure 2: Model implication: Inflation and Velocity

to 5 can match the observation well. Interestingly, setting $\chi$ to 0.5 is consistent with the estimated Frisch elasticity found in empirical micro studies.

Per-period velocity is measured by

$$
\int_{0}^{\infty} \frac{1}{\phi(\omega)} Y(m, \omega) \omega(d m)+\sigma \int_{0}^{\infty} \int_{0}^{\infty} d(m, \tilde{m}, \nu) \nu(d m) \nu(d \tilde{m})
$$

Figure (2) shows the relationship between inflation and velocity implied by the model in the stationary equilibrium. We begin by characterizing a stationary equilibrium. Figure (3) shows the equilibrium policy functions in the centralized market for the case of zero inflation. Note that the money demand, $m_{+1}(m, \omega)$, and consumption, $X(m, \omega)$, are increasing in $m$ while the production, $Y(m, \omega)$, is decreasing in $m$. In contrast, due to the quasi-linearity 

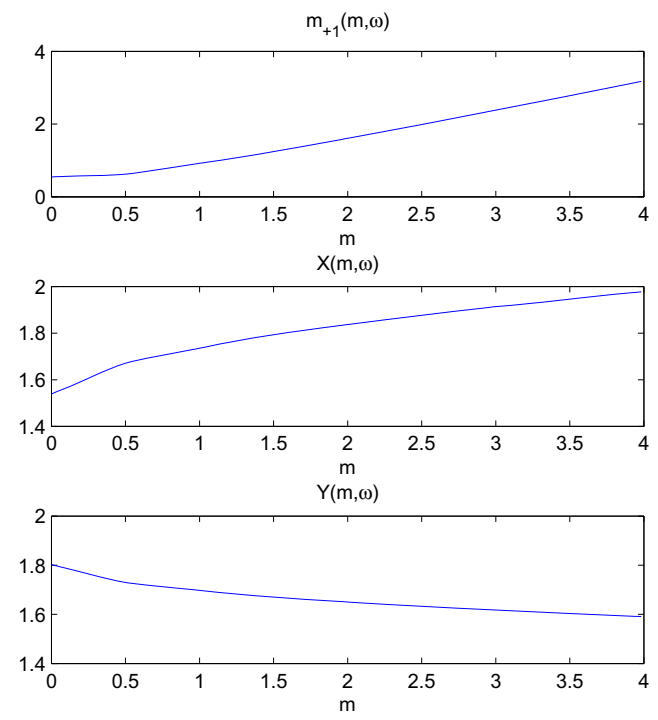

Figure 3: Policy functions in CM

assumption, these choices are independent of individual money holdings in the Lagos-Wright model.

Figure (4) and (5) show the terms of trade functions, $d\left(m_{b}, m_{s}\right)$ and $q\left(m_{b}, m_{s}\right)$. These functions are different from that of the Lagos-Wright model in which the constant marginal value of money in the centralized market (due to the quasi-linear preference) implies that the terms of trade are independent of the seller's money holding. In our model, the marginal value of money is diminishing and, as a result, the quantity of goods traded $(q)$ is increasing in the buyer's money holding $\left(m_{b}\right)$, but decreasing in the seller's money holding $\left(m_{s}\right)$. Also, the amount of money traded $(d)$ is increasing in both agents' money holdings.

Figure (6) illustrates the monetary distribution at the beginning of the period, $\nu(m)$. In Lagos and Wright, the quasi-linear preference implies that all agents choose the same money demand, resulting in a degenerate monetary distribution. In our model, the convex cost function in the centralized market discourages agents from perfectly undoing their idiosyncratic trading histories, resulting in a non-degenerate monetary distribution.

Since the model is aimed at examining the distributional effects of monetary policy, one 


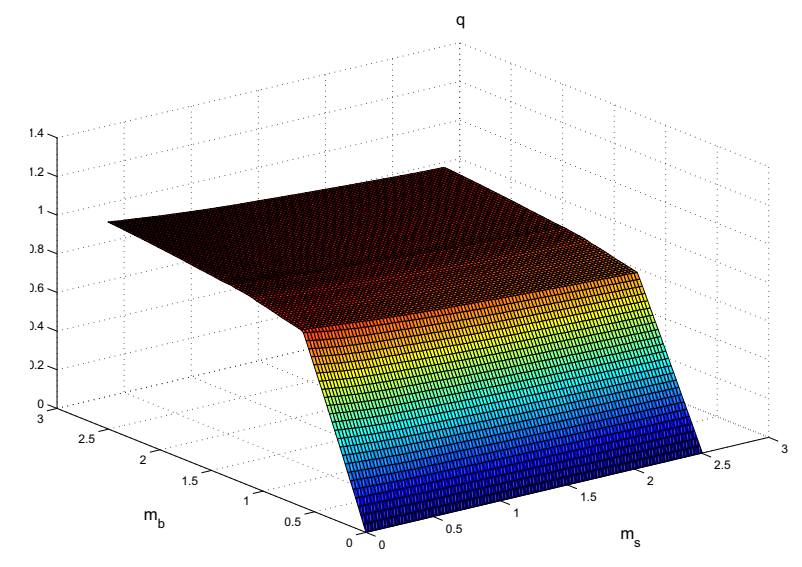

Figure 4: Terms of trade: $q\left(m_{b}, m_{s}\right)$

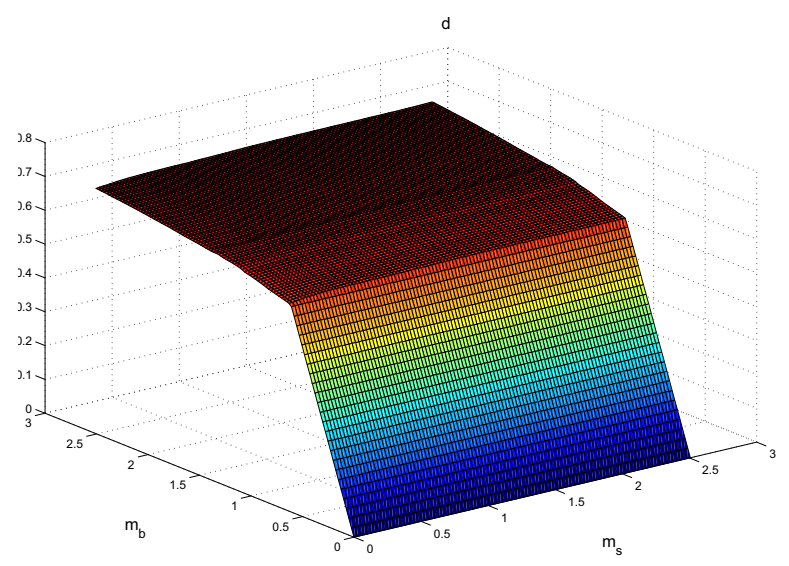

Figure 5: Terms of trade: $d\left(m_{b}, m_{s}\right)$
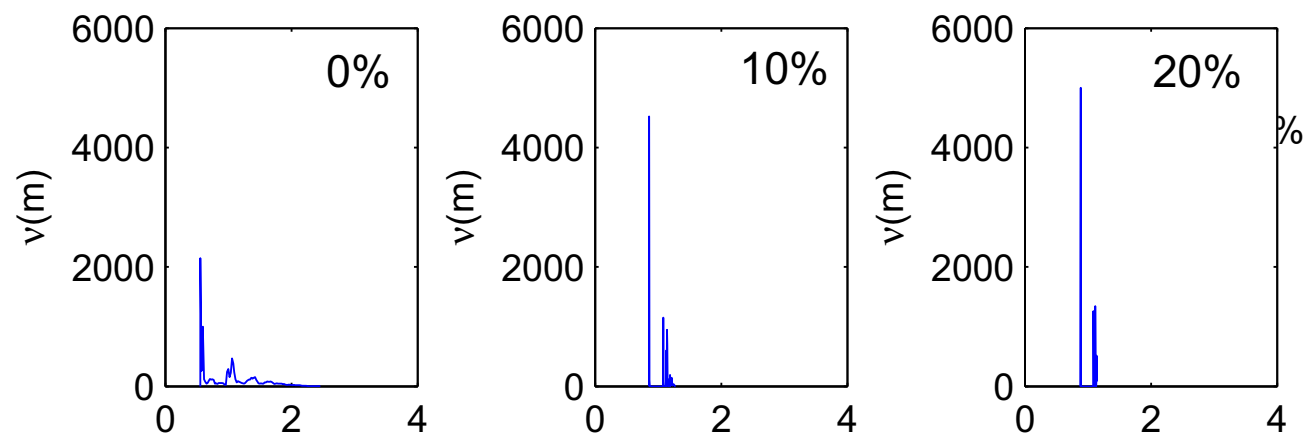

Figure 6: Monetary Distribution $\nu(m)$ 
should make sure that the monetary distribution implied by the model is able to capture certain dimensions of the actual cross-sectional money distribution. There are, however, two difficulties involved. First, the data on the distribution of money holdings is limited. ${ }^{14}$ Second, the model focuses on transitory shocks and abstracts from other uninsurable persistent shocks which are probably related to the long right tail of the empirical distribution.

To get an idea about the dispersion in the empirical monetary distribution, we use the data from the 2004 Survey of Consumer Finance to obtain the distributions of chequing and transaction account balances across U.S. households as a proxy. ${ }^{15}$ The $10^{\text {th }}, 90^{\text {th }}$ and $100^{\text {th }}$ percentiles of these two distributions are shown in Table 5, together with the same percentiles implied by the model. ${ }^{16}$ As shown in the table, this model is unable to match the long tail of the upper end of the empirical distribution. But the distribution implied by the model can match the tenth percentile and the ninetieth percentile relatively well.

\begin{tabular}{|c|c|c|c|}
\hline Percentile & Model & Chequing account (Data) & Transaction account (Data) \\
\hline \hline $10^{\text {th }}$ & 0.05 & 0.00 & 0.00 \\
$90^{\text {th }}$ & 2.05 & 1.90 & 1.80 \\
$100^{\text {th }}$ & 2.23 & 4695.50 & 1894.10 \\
\hline $90^{\text {th }}-10^{\text {th }}$ & 2.00 & 1.90 & 1.80 \\
\hline
\end{tabular}

We now consider the effects of inflation on the stationary monetary equilibrium. Table 2 reports the outcomes of the stationary equilibrium for annualized inflation rates of $-2 \%$, $0 \%, 2 \%, 10 \%$, and $20 \%$. With higher inflation, the price of money in terms of the general good in the centralized market, in general, goes down. Since inflation increases buyers' cost of the special goods in the decentralized market, the average consumption and the relative size of the decentralized market go down. As agents economize on their money holdings, the money demand drops and the velocity of money rises. Figure (6) plots the effect of money

\footnotetext{
${ }^{14}$ For example, there is no good data on currency distribution.

${ }^{15}$ In this survey, chequing accounts do not include money market accounts. Transaction accounts consist of money market, chequing, saving and call accounts.

${ }^{16}$ In the table, the money distribution of the model refers to that of the weighted average of the individual money holdings across the two markets, with the weights given by the output shares of the two markets.
} 
growth on the money distributions $\nu(m)$. In general, as the money growth rate increases, the distribution collapses to a degenerate distribution, as in the case of Lagos and Wright.

Table 2: Effects of Monetary Policy

\begin{tabular}{|l|c|c|c|c|c|c|}
\hline Rate of Inflation & $\mathbf{- 2 \%}$ & $\mathbf{0 \%}$ & $\mathbf{1 \%}$ & $\mathbf{2 \%}$ & $\mathbf{1 0 \%}$ & $\mathbf{2 0 \%}$ \\
\hline \hline Price of Money & 0.71 & 0.48 & 0.43 & 0.39 & 0.26 & 0.22 \\
\hline Average consumption in DM & 0.92 & 0.87 & 0.84 & 0.83 & 0.72 & 0.62 \\
\hline Size of DM (\% of GDP) & $8.58 \%$ & $8.23 \%$ & $8.05 \%$ & $7.93 \%$ & $7.00 \%$ & $6.08 \%$ \\
\hline Velocity & 2.63 & 3.88 & 4.36 & 4.72 & 7.10 & 8.23 \\
\hline Money Demand/GDP & 0.38 & 0.26 & 0.23 & 0.21 & 0.14 & 0.12 \\
\hline
\end{tabular}

Now we study the welfare effects of monetary expansion. We will measure the welfare cost of inflation by deriving how much consumption agents would be willing to sacrifice to reduce inflation to $0 \%$. Using $X_{\mu}, Y_{\mu}, q_{\mu}, d_{\mu}, \nu_{\mu}$ and $\omega_{\mu}$ to denote the functions and distributions in an equilibrium with inflation rate $\mu-1$, we can define the average expected value with inflation rate $\mu-1$ as

$$
\begin{aligned}
\bar{U}(\mu)=(1-\beta)^{-1}\left\{\sigma \int_{0}^{\infty} \int_{0}^{\infty}[\right. & \left.u\left(q_{\mu}\left(m, \tilde{m}, \nu_{\mu}\right)\right)-q_{\mu}\left(m, \tilde{m}, \nu_{\mu}\right)\right] \nu_{\mu}(d m) \nu_{\mu}(d \tilde{m}) \\
& +\int_{0}^{\infty}\left[U\left(X_{\mu}\left(m, \omega_{\mu}\right)\right)-C\left(Y_{\mu}\left(m, \omega_{\mu}\right)\right] \omega_{\mu}(d m)\right\} .
\end{aligned}
$$

Then the welfare cost of having money growth rate $\mu$ relative to zero inflation is given by $1-\Delta_{0}(\mu)$ where $\Delta_{0}(\mu)$ solves

$$
\begin{array}{r}
\bar{U}(\mu)=(1-\beta)^{-1}\left\{\sigma \int_{0}^{\infty} \int_{0}^{\infty}\left[u\left[q_{0}\left(m, \tilde{m}, \nu_{0}\right) \Delta_{0}(\mu)\right]-q_{0}\left(m, \tilde{m}, \nu_{0}\right)\right] \nu_{0}(d m) \nu_{0}(d \tilde{m})\right. \\
\left.+\int_{0}^{\infty}\left[U\left(X_{0}\left(m, \omega_{0}\right)\right)-C\left(Y_{0}\left(m, \omega_{0}\right)\right)\right] \omega_{0}(d m)\right\} .
\end{array}
$$

\section{Welfare cost of inflation}

First, given the parameter values, we find that the welfare cost of $10 \%$ inflation is $1-$ $\Delta_{0}(10 \%)=0.59 \%$ of output, as reported in table (3). This number is $40 \%$ lower than 

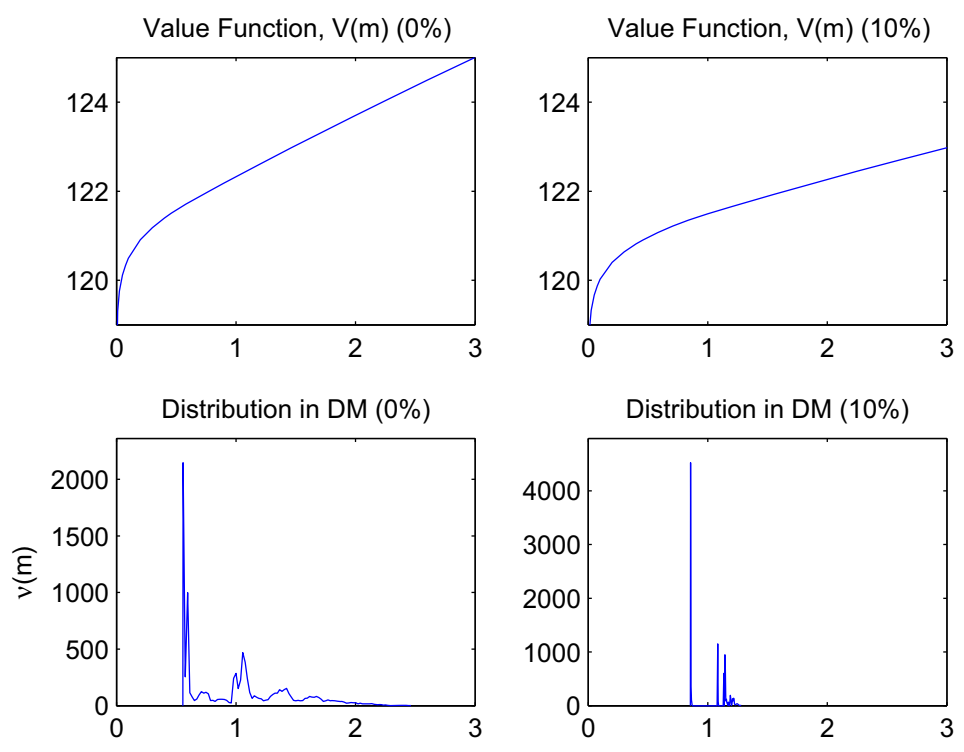

Figure 7: Value Function $V$ and Distribution $\nu$ in DM

the estimate of Lucas (around 1\%) and 55\% lower than that of Lagos and Wright (1.3\%) (for the same pricing mechanism as we use in this paper). In these representative agent models, expansionary monetary policy through lump sum money transfers only has realbalance effects, but not any distributional effects. However, in a heterogenous agent model, an these expansionary monetary policy can redistribute real money balances from liquidityrich agents to liquidity-poor agents and condense the monetary distribution (Figure (7)). This redistribution effect tends to raise the average welfare in the economy.

One may mechanically decompose the inflation effects on the average utility into two parts: the effect of changing the distribution and the effect of changing the decision rules. For example, Figures (8) and (9) decompose the change in average utility in the decentralized market as inflation goes up from $0 \%$ to $10 \%$ into the change in the distribution and the change in the quantity of goods traded. In these graphs, the joint distribution of buyers and sellers' money holdings is represented by dots and the quantities of goods traded, $q\left(m_{b}, m_{s}\right)$ is represented by the contour lines. As shown, higher inflation rate condenses the money distribution, and also lowers the quantity of trade in a match. Similarly, Figures (10) and 
Table 3: Welfare Cost of Inflation (relative to to 0\%)

\begin{tabular}{|l|c|c|c|c|}
\hline Rate of inflation & $\mathbf{1 \%}$ & $\mathbf{2 \%}$ & $\mathbf{1 0 \%}$ & $\mathbf{2 0 \%}$ \\
\hline $\begin{array}{l}\text { Distribution } \nu \text { in DM } \\
\text { - } 90^{\text {th }} \text { percentile }-10^{\text {th }} \text { percentile }\end{array}$ & 1.00 & 0.90 & 0.34 & 0.26 \\
\hline $\begin{array}{l}\text { Average price of goods } \\
\text { - in decentralized market }\end{array}$ & 0.83 & 0.91 & 1.38 & 1.60 \\
- in centralized market & 2.33 & 2.56 & 3.85 & 4.55 \\
\hline \hline Welfare cost & $0.08 \%$ & $0.14 \%$ & $0.59 \%$ & $0.88 \%$ \\
\hline Welfare Change (\% of consumption ), due to & & & & \\
- change in distribution only & +0.04 & +0.11 & +0.74 & +0.79 \\
- change in both distribution and decision rules & -0.08 & -0.14 & -0.59 & -0.88 \\
\hline
\end{tabular}

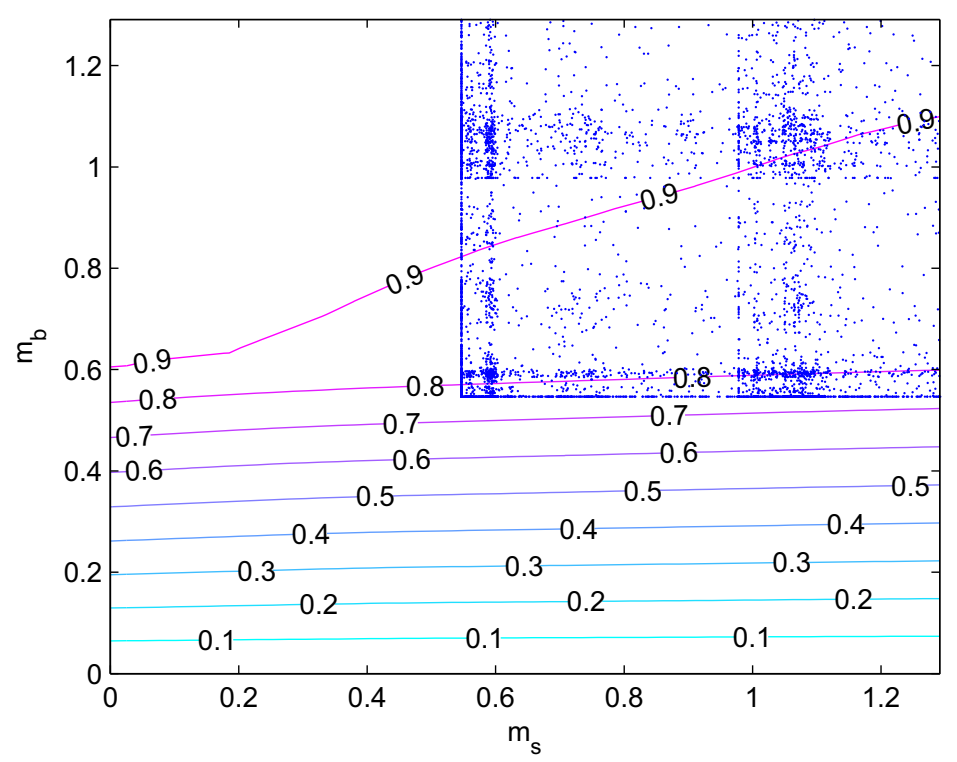

Figure 8: Quantity $q\left(m_{b}, m_{s}\right)$ Contours and Money Distribution in DM (0\%)

(11) decompose the change in the average utility in the centralized market. These two will combine to generate the change in the average (total) utility, as reported in Figure (7).

The average utility in a steady state equilibrium with an inflation rate $\mu$ can be written as 


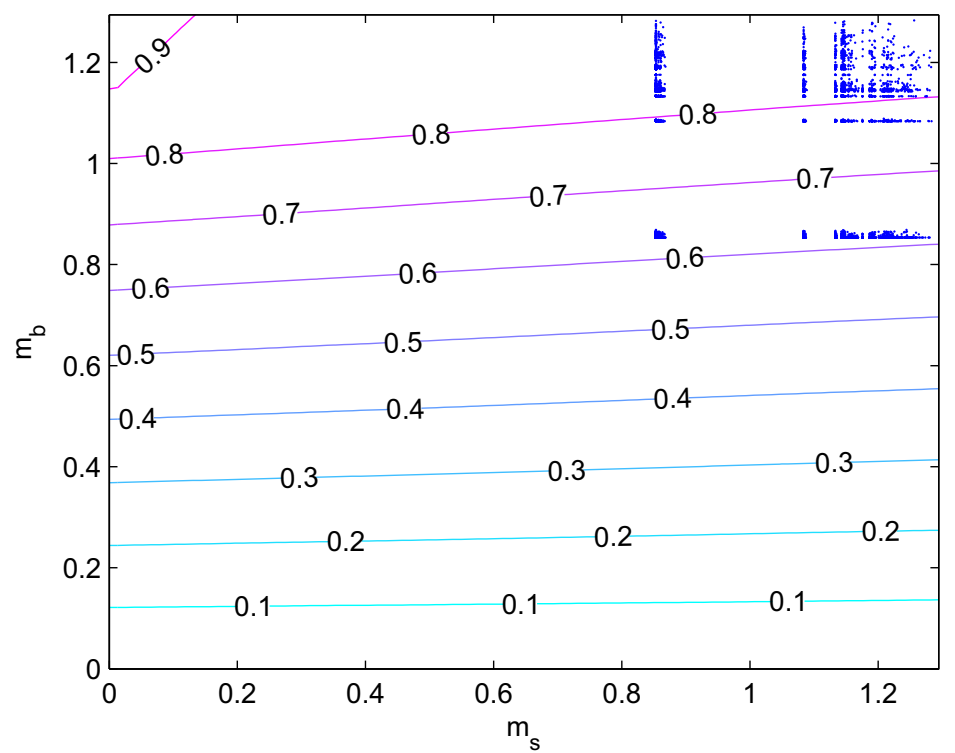

Figure 9: Quantity $q\left(m_{b}, m_{s}\right)$ Contours and Money Distribution in DM (10\%)
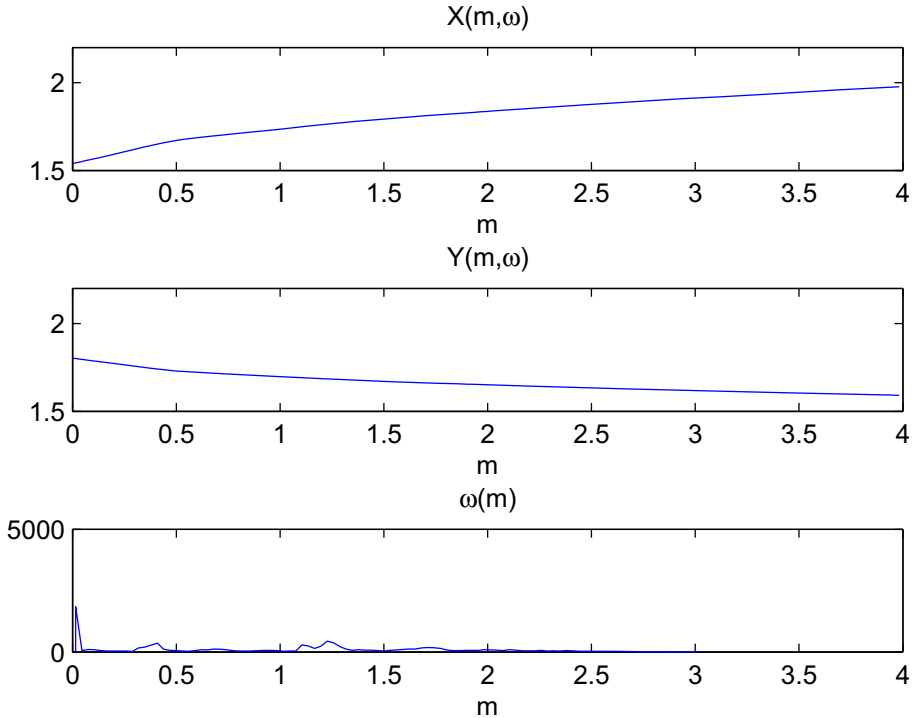

Figure 10: Decision Rules and Money Distribution in CM (0\%) 

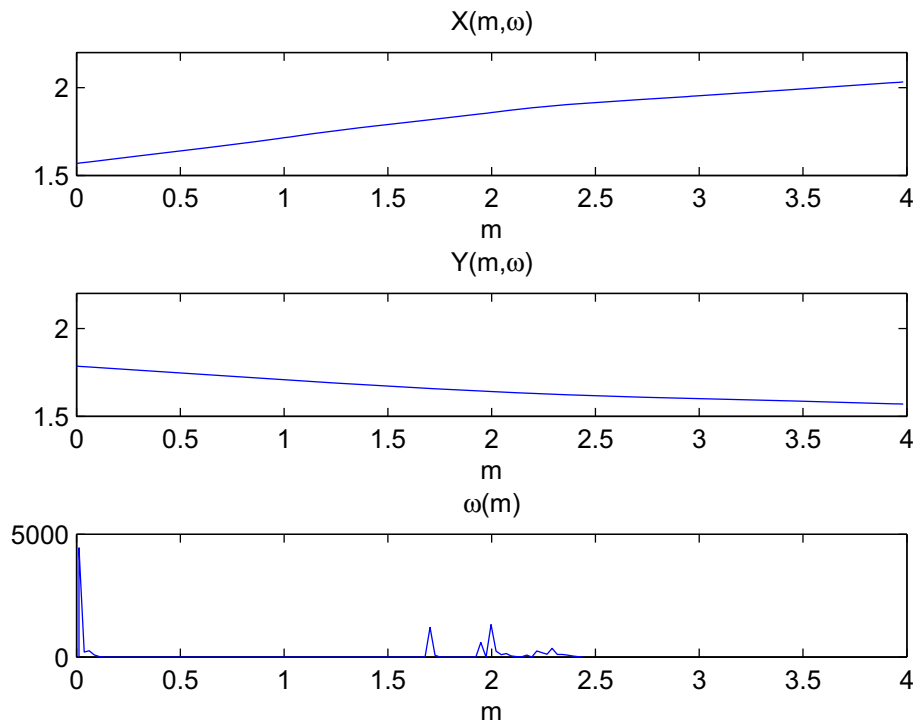

Figure 11: Decision Rules and Distribution in CM (10\%)

$$
\begin{aligned}
& \bar{U}(\mu)=(1-\beta)^{-1} \frac{1}{2} \int_{0}^{\infty} \int_{0}^{\infty}\{\overbrace{[\underbrace{u\left(q_{\mu}(m, \tilde{m})\right)}_{\text {consumption in DM }}+\underbrace{U\left(X_{\mu}\left(m-d_{\mu}(m, \tilde{m})\right)\right)-C\left(Y_{\mu}\left(m-d_{\mu}(m, \tilde{m})\right)\right)}_{\text {consumption and production in CM }}}^{\text {BUYER }} \\
& \text { SELLER }
\end{aligned}
$$

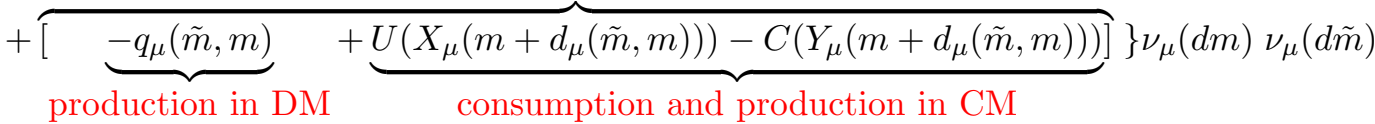

$$
\begin{aligned}
& \equiv(1-\beta)^{-1} \frac{1}{2} \int_{0}^{\infty} \int_{0}^{\infty}\left\{\Lambda\left(m, \tilde{m}, q_{\mu}(m, \tilde{m}), d_{\mu}(m, \tilde{m}), X_{\mu}(m), Y_{\mu}(m)\right)\right\} \nu_{\mu}(d m) \nu_{\mu}(d \tilde{m}) .
\end{aligned}
$$

In particular, when the inflation rate is 0 , the average utility is given by:

$\bar{U}(0)=(1-\beta)^{-1} \frac{1}{2} \int_{0}^{\infty} \int_{0}^{\infty}\left\{\Lambda\left(m, \tilde{m}, q_{0}(m, \tilde{m}), d_{0}(m, \tilde{m}), X_{0}(m), Y_{0}(m)\right)\right\} \nu_{0}(d m) \nu_{0}(d \tilde{m})$

Inflation can change the average utility by either changing the distribution of money holdings (i.e. $\left.\nu_{\mu}\right)$ or the decision rules (i.e. $\left.q_{\mu}(m, \tilde{m}), d_{\mu}(m, \tilde{m}), X_{\mu}(m), Y_{\mu}(m)\right)$. Here, we 
can mechanically perform the following experiment: changing the distribution of money across agents, but holding the decision rules unchanged. In particular, we use the (old) decision rules $\left(q_{0}(m, \tilde{m}), d_{0}(m, \tilde{m}), X_{0}(m), Y_{0}(m)\right)$ associated with a steady state equilibrium with a $0 \%$ inflation to derive the average utility implied by the (new) monetary distribution associated with a steady state equilibrium with a $10 \%$ inflation $\left(\nu_{\mu}\right)$ :

$\bar{U}^{\nu}=(1-\beta)^{-1} \frac{1}{2} \int_{0}^{\infty} \int_{0}^{\infty}\left\{\Lambda\left(m, \tilde{m}, q_{0}(m, \tilde{m}), d_{0}(m, \tilde{m}), X_{0}(m), Y_{0}(m)\right)\right\} \nu_{\mu}(d m) \nu_{\mu}(d \tilde{m})$

Table (3) shows that, as inflation increases, the distribution of money holdings becomes less dispersed and the purchasing power of money goes down. The combined outcome is that the welfare cost goes up. Using the decomposition discussed above, we can see that changing distribution alone tends to raise the average utility, but this positive effect is always offset by the change in the decision rules. As a result, the welfare cost of inflation is always positive. Furthermore, as inflation increases, the money distribution becomes less dispersed. As a result, the marginal redistributive effect of inflation is diminishing in the inflation rate (Figure (12)).

\section{Price Distribution and Inflation}

Figures (13)-(15) report the effect of inflation on the distribution of normalized prices, which is the price of goods in each trade divided by the average price in the decentralized market. The normalized price distribution becomes less dispersed as inflation goes up. This is due to the changes in the underlying money distribution, as shown in Figure (16)-(18).

\section{Frisch elasticity of labor supply and effects of monetary policy}

This section discusses the relationship between the Frisch elasticity of labor supply and welfare effects of inflation. Figure (19) and Table (4) report the implications of the model as we change the Frisch elasticity of labor supply, captured by $\chi$. We use our benchmark calibration and change $\chi$ from infinity to 0.01. As illustrated in Figure (19), increasing $\chi$ 


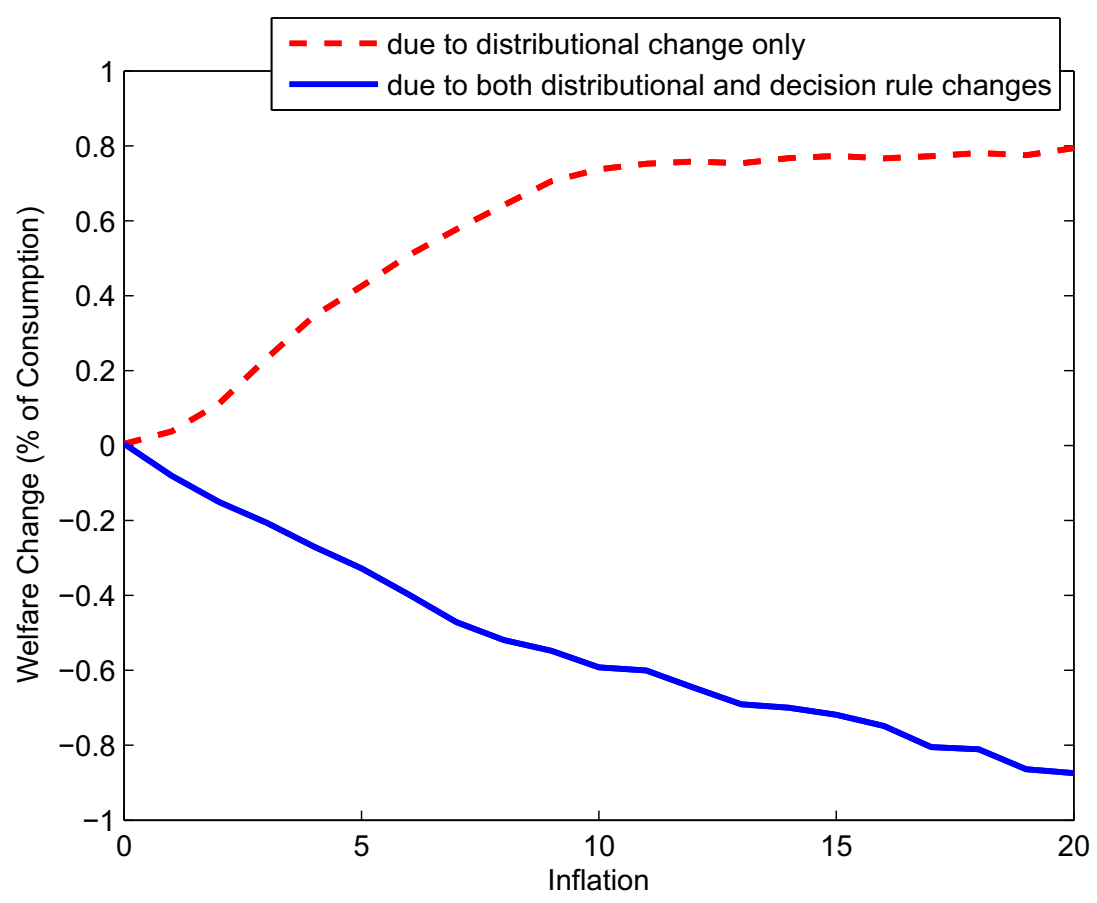

Figure 12: Decomposition of Inflation Effect on Welfare

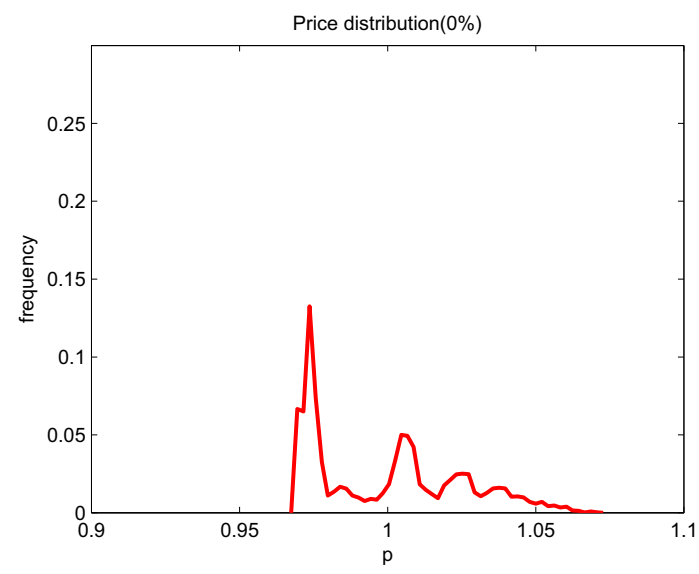

Figure 13: Normalized Price Distribution in DM (0\%) 


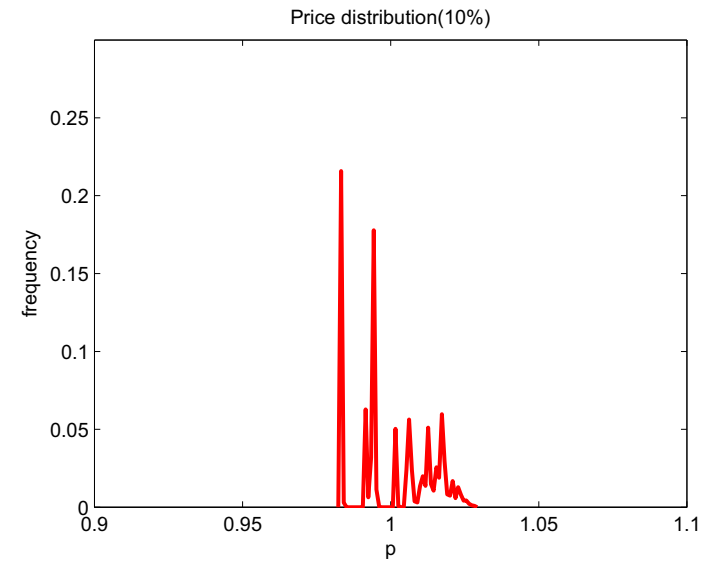

Figure 14: Normalized Price Distribution in DM (10\%)

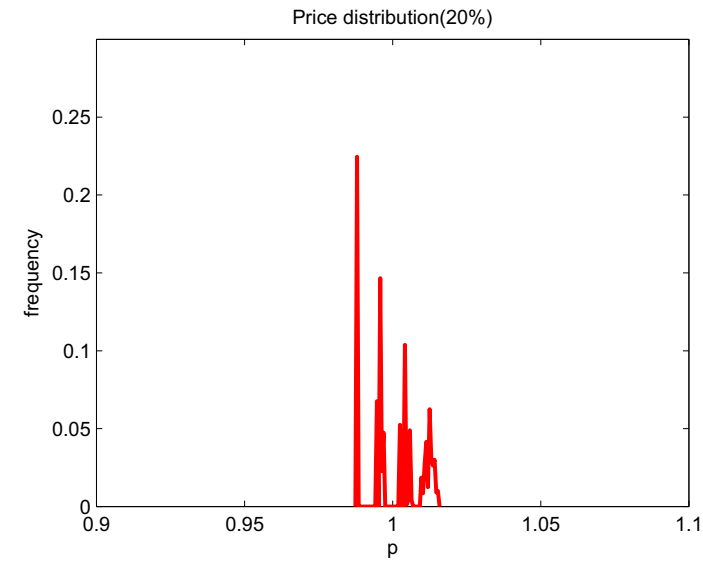

Figure 15: Normalized Price Distribution in DM (20\%)

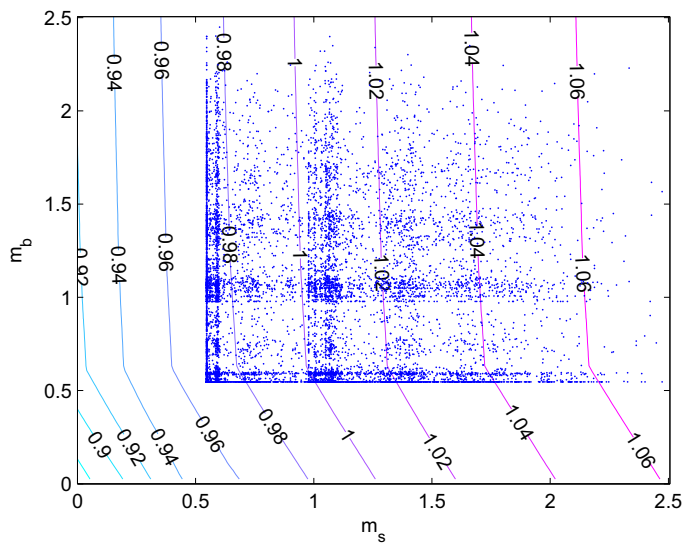

Figure 16: Normalized Price Contours and Money Distribution in DM (0\%) 


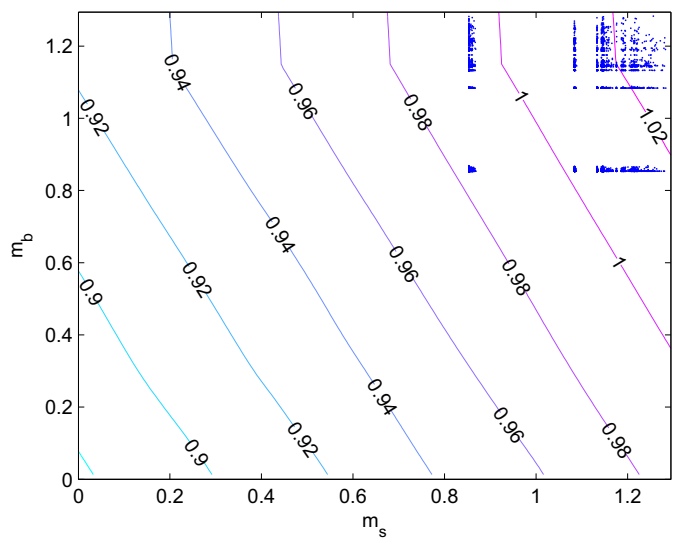

Figure 17: Normalized Price Contours and Money Distribution in DM (10\%)

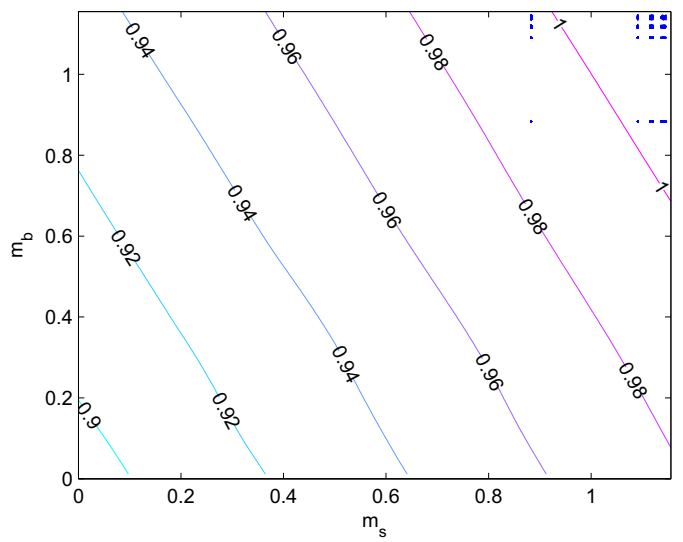

Figure 18: Normalized Price Contours and Money Distribution in DM (20\%) 


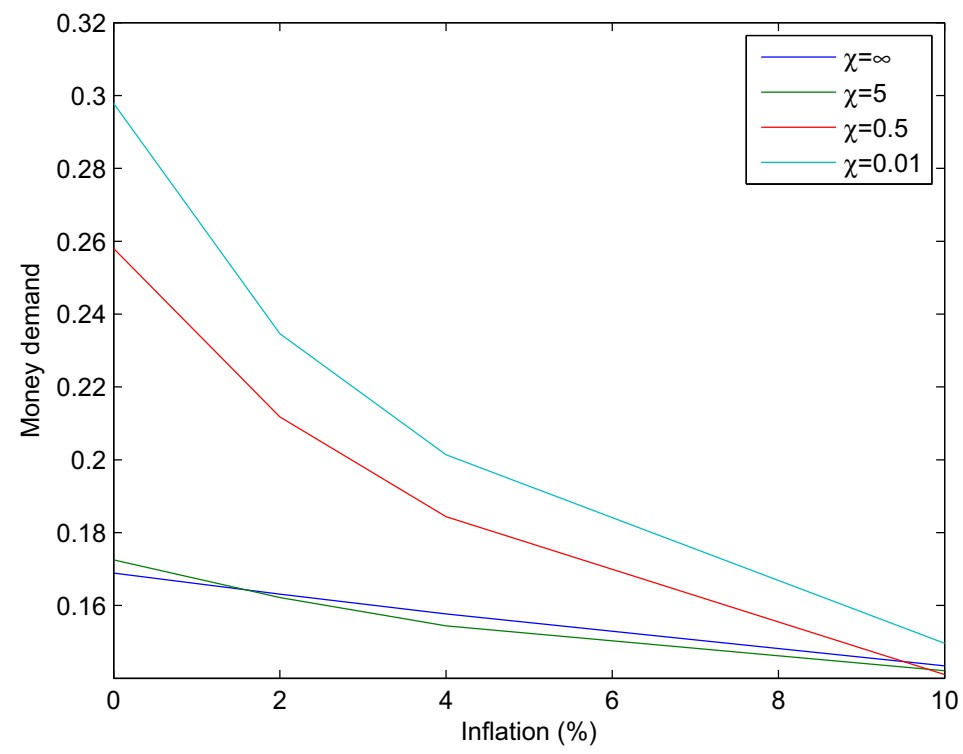

Figure 19: Money Demand and the Degree of Market Incompleteness

Table 4: Frisch elasticity of labor supply and effects of monetary policy

\begin{tabular}{|l|c|cccc|}
\hline & $\mu$ & $\chi=\infty$ & $\chi=5$ & $\chi=0.5$ & $\chi=0.01$ \\
\hline Money Demand & $0 \%$ & 0.17 & 0.17 & 0.26 & 0.30 \\
& $2 \%$ & 0.16 & 0.16 & 0.21 & 0.23 \\
& $10 \%$ & 0.14 & 0.14 & 0.14 & 0.15 \\
\hline 90th percentile - 10th percentile in DM & $0 \%$ & 0.00 & 0.23 & 1.11 & 1.24 \\
& $2 \%$ & 0.00 & 0.08 & 0.90 & 1.10 \\
& $10 \%$ & 0.00 & 0.09 & 0.34 & 0.61 \\
\hline Welfare cost & $2 \%$ & 0.03 & 0.04 & 0.14 & 0.17 \\
& $10 \%$ & 0.25 & 0.22 & 0.59 & 0.72 \\
\hline
\end{tabular}

makes the demand for money less responsive to inflation. Also, as $\chi$ reduces, the monetary distribution becomes more dispersed, and the welfare cost of inflation goes up.

\section{Comparative Static Experiment using the Lagos-Wright parameters}

Here, we take the Lagos-Wright model (i.e. $\chi=\infty$ ) as a benchmark and perform comparative static exercise as we adjust the parameter $\chi$. We use the following set of parameter values calibrated in Lagos and Wright (2005): $\theta=1, \sigma=0.5, \eta=0.16, B=1.97$. As we reduce the parameter $\chi$, money demand becomes more responsive to inflation, and the monetary distribution in the decentralized market becomes more dispersed. Even though 
Table 5: Comparative Static Experiment (Lagos-Wright parameters)

\begin{tabular}{|c|c|c|c|c|}
\hline & $\chi=\infty$ & $\chi=10000$ & $\chi=100$ & $\chi=1$ \\
\hline $\begin{array}{l}\text { Distribution } \nu \text { in } \mathbf{D M} \\
90^{\text {th }} \text { percentile }-10^{\text {th }} \text { percentile }\end{array}$ & & & & \\
\hline - $0 \%$ inflation & 0.00 & 0.00 & 0.07 & 1.48 \\
\hline - $10 \%$ inflation & 0.00 & 0.00 & 0.02 & 0.63 \\
\hline $\begin{array}{l}\text { Average quantity in DM } \\
\text { - } 0 \% \text { inflation } \\
\text { - } 10 \% \text { inflation }\end{array}$ & $\begin{array}{l}0.61 \\
0.20\end{array}$ & $\begin{array}{l}0.60 \\
0.20\end{array}$ & $\begin{array}{l}0.60 \\
0.20\end{array}$ & $\begin{array}{l}0.47 \\
0.17\end{array}$ \\
\hline $\begin{array}{l}\text { Money demand } \\
\text { - } 0 \% \text { inflation } \\
\text { - } 10 \% \text { inflation }\end{array}$ & $\begin{array}{l}0.27 \\
0.10\end{array}$ & $\begin{array}{l}0.27 \\
0.10\end{array}$ & $\begin{array}{l}0.26 \\
0.10\end{array}$ & $\begin{array}{l}0.29 \\
0.08\end{array}$ \\
\hline Welfare Cost & 1.45 & 1.45 & 1.41 & 1.13 \\
\hline $\begin{array}{l}\text { Welfare Change, due to } \\
\text { - change in dist. } \nu \text { only } \\
\text { - change in dist. and dec rules }\end{array}$ & $\begin{array}{c}0.00 \\
-1.45\end{array}$ & $\begin{array}{c}0.00 \\
-1.45\end{array}$ & $\begin{array}{l}+0.01 \\
-1.41\end{array}$ & $\begin{array}{l}+0.09 \\
-1.13\end{array}$ \\
\hline
\end{tabular}

money demand is more sensitive to inflation, the welfare cost goes down. Again, the change in decentralized market distribution always has a positive effect on the average utility.

\section{Discussion and Conclusion}

This paper studies the welfare costs and the redistributive effects of inflation in the presence of idiosyncratic liquidity risk, in a micro-founded search-theoretical monetary model. We calibrate the model to match the empirical aggregate money demand, compare the implied distribution of money holdings across households with the empirical distribution, and study the effects of inflation under the implied degree of market incompleteness. We show that in the presence of imperfect insurance the estimated long-run welfare costs of inflation are on average $40 \%$ smaller compared to a complete markets, representative agent economy, and that inflation induces important redistributive effects across households. We estimate that the long-run welfare gains of reducing inflation from 2 to 1 percent to be $0.06 \%$ of income. 


\section{References}

Alvarez, Fernando, Andrew Atkeson and Chris Edmond. (2003). "On the Sluggish Response of Prices to Money in an Inventory-Theoretic Model of Money Demand," NBER Working Paper No. w10016.

Alvarez, Fernando, Andrew Atkeson and Patrick J. Kehoe.(2002). "Money, Interest Rates, and Exchange Rate, with Endogeneously Segmented Markets", Journal of Political Economy 110, 73-112.

Bailey, Martin J. (1956). "The Welfare Cost of Inflationary Finance," Journal of Political Economy 64, 93-110.

Baumol, William J. (1952). "The Transactions Demand for Cash: An Inventory Theoretical Approach," Quarterly Journal of Economics 66, 545-56.

Berentsen, Aleksander, Gabriele Camera and Christopher Waller. (2005). "The Distribution Of Money Balances And The Nonneutrality Of Money", International Economic Review 46, 465-87.

Chiu, Jonathan. (2005). "Endogenously Segmented Asset Market in an Inventory Theoretic Model of Money Demand", mimeo, The University of Western Ontario.

Chiu, Jonathan and Miguel Molico. (2006). "Endogenous Asset Market Participation and Random Matching in an Inventory Model of Money Demand", manuscript.

Deviatov, Alexei and Neil Wallace. (2001). "Another Example in Which Lump-sum Money Creation Is Beneficial," Advances in Macroeconomics 1, Article 1.

Ennis, Huberto. (2005). "Avoiding the Inflation Tax", Working Paper, Federal Reserve Bank of Richmond Working Paper 05-10.

Friedman, Milton. (1969). 'The Optimum Quantity of Money and Other Essays. Chicago: Aldine.

Grossman, Sanford J, and Weiss, Laurence. (1983). "A Transactions-Based Model of the Monetary Transmission Mechanism", American Economic Review 73, 871-80.

İmrohoroğlu, Ayşe. (1992). "The Welfare Cost of Inflation Under Imperfect Insurance," 
Journal of Economic Dynamics and Control 16, 79-91.

Jovanovic, Boyan. (1982). "Inflation and Welfare in the Steady State," Journal of Political Economy 90, 561-77.

Khan, Aubhik and Julia Thomas. (2005). "Inflation and Interest Rates with Endogenous Market Segmentation", manuscript.

Lagos, Ricardo and Randall Wright. (2005). "A United Framework for Monetary Theory and Policy Analysis", Journal of Political Economy 113, 463-484.

Levine, David. (1991). "Asset Trading Mechanisms and Expansionary Policy," Journal of Economic Theory 54, 148-64.

Lucas, Robert. (2000). "Inflation and Welfare", Econometrica 68, p. 247-274.

Metcalf, Cherie, Angela Redish, and Ronald Shearer. (1998). "New Estimates of the Canadian Money Stock, 1987-1967," The Canadian Journal of Economics 31, 104-124.

Molico, Miguel. (2006). "The Distribution of Money and Prices in Search Equilibrium", International Economic Review 47, 701-722.

Rocheteau, Guillaume, Rupert, Peter, Shell, Karl and Wright, Randall D. (2005) "General Equilibrium With Nonconvexities, Sunspots, and Money". FRB of Cleveland Working Paper No. 05-13.

Rogerson, Richard, (1988). "Indivisible labor, lotteries and equilibrium", Journal of Monetary Economics, Elsevier, vol. 21(1), pages 3-16, January.

Romer, David. (1986). "A Simple General Equilibrium Version of the Baumol-TobinModel," Quarterly Journal of Economics 101, 66385.

Serletis, Apostolos, and Kazem Yavari. (2004). "The Welfare Cost of Inflation in Canada and the United States," Economic Letters 84, 199-204.

Tobin, James. (1956). "The Interest-Elasticity of Transactions Demand for Money," Review of Economics and Statistics 38, 241-47.

Telyukova, I. and R. Wright. (2005). "A Model of Money and Credit, with Application to the Credit Card Debt Puzzle", University of Pennsylvania working paper. 
Williamson, Stephen. (2006). "Search, Limited Participation, and Monetary Policy", International Economic Review 47, 107-128. 